\title{
Experience of a Tertiary-Level Urology Center in the Clinical Urological Events of Rare and Very Rare Incidence. IV. Urological Surprises: 1. Ectopic Renal Pain
}

ISSN: 2578-0395

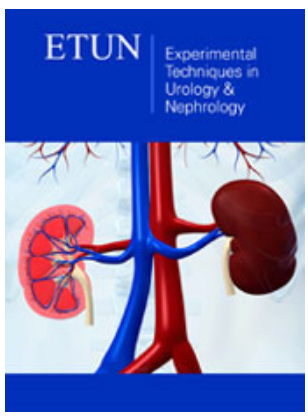

*Corresponding author: Gadelkareem RA, Assiut Urology and Nephrology Hospital, Assiut University, Assiut, Egypt. 71515; dr.rabeagad@yahoo.com

Submission: 制 February 09, 2019

Published: 㘹March 14, 2019

Volume 2 - Issue 5

How to cite this article: Gadelkareem R, Abdelhafez M, Shahat A, Osman M, Abdelgawad A, Elgammal M, Sayed M. Experience of a Tertiary-Level Urology Center in the Clinical Urological Events of Rare and Very Rare Incidence. IV. Urological Surprises: 1. Ectopic Renal Pain. Exp Tech Urol Nephrol. 2(5). ETUN.000548.2019. DOI: 10.31031/ETUN.2019.02.000548

Copyright@ Gadelkareem RA, This article is distributed under the terms of the Creative Commons Attribution 4.0 International License, which permits unrestricted use and redistribution provided that the original author and source are credited.

\section{Gadelkareem RA*, Abdelhafez MF, Shahat AA, Osman MM, Abdelgawad AM, Elgammal MA and Sayed MA}

Assiut Urology and Nephrology Hospital, Faculty of Medicine, Assiut University, Assiut, Egypt

\begin{abstract}
Purpose: To present our center's experience with the implications of the unusual presentation of renal pain as the first presenting clinical symptom.

Material and methods: A retrospective search of the patients' records during the period July 2001 - June 2016 was done in our center for the reported cases of isolated unusual (ectopic) first clinical presentation of renal pain or colic. Cases with abnormal underlying anatomy in the upper urinary tract and those who did not present firstly with isolated unusual renal pain were excluded. Each case was studied for the relevant demographic and clinical variables from the site of pain to the management approach.
\end{abstract}

Result: Of more than 135,000 cases of loin pain, only 24 patients (15 males and 9 females) presented with unusual renal pain between July 2001 and June 2016. They were classified into distant-site referral of pain in 15 cases (62.5\%) and renal pain due to unusual extra-urological causes in 9 cases (37.5\%). The former group included contralateral renal pain in 3 cases (12.5\%), epigastric cramps in 3 cases (12.5\%), low-back pain in 4 cases (16.7\%), and contralateral testicular pain in 5 cases $(20.8 \%)$. The latter group included cases of refractory acute ischemic renal pain as the first presentation of other system pathologies in 5 cases (20.8\%) and referred biliary pain in 4 cases (16.7\%). All cases warranted multiple medical visits and most of them indicated extra laboratory and/or imaging examinations till the final diagnosis.

Conclusion: Ectopic renal pain could be either an isolated distant-site referred pain which is mostly served by common innervation between nerve plexuses or pain due to unusual renal involvement by other system pathology. It may delay the original diagnosis and indicate undue diagnostic works up.

Keywords: Clinical presentations; Ectopic pain; Neuromuscular reflex; Referred pain; Renal colic; Renal pain

\section{Introduction}

Clinical presentations of diseases are classified into two well-differentiated categories known as symptoms and signs. The former category is the subjective disease expressions by the patient and the latter category is the objective disease findings detected by the examiner [1]. Symptoms may be physical complaints such as abnormal swellings [2] or sensual complaints such as pain [3]. They are classically limited to the underlying anatomical boundaries of the affected structure, organ, or system and the pathophysiological behaviors of the disease. On the one hand, site of the first clinical presenting symptom usually refers to the involved anatomical structures guided by the relations to the surface anatomy of these affected organs or structures [4], but on the other clinical progress of symptoms over time follows the natural history of the underlying disease. In certain instances, however, symptoms may not keep fit to the known anatomical boundaries and natural histories [3-5]. Moreover, they may have underlying aberrant or unknown mechanisms which may result in clinical surprises. Also, the sequences and associations between clinical findings depend on the behavior of the disease through the progress of stages of its natural history [5,6]. Relations between the upper urinary tract and biliary and gastrointestinal tracts are old principles and may lead to unusual clinical presentations $[7,8]$. Renal pain is the most prominent urological symptom that has different forms of clinical presentation or confusions with other diseases due to their rarity 
and the similarity between them $[9,10]$. We aimed to study the very rare clinical phenomenon of first clinical presentation with isolated unusual renal pain to widen the horizon of differential diagnoses for the clinical urologists in emergency settings.

\section{Materials and Methods}

Retrospective search was done for the medical records of the patients who presented to or admitted in our hospital during the period July 2001-June 2016 to study the cases of first clinical presentation with atypical or unusual renal pain which was termed "ectopic renal pain". Searches and reviews of the manual chart and electronic medical records were done by two different individuals of authors to avoid controversy of data extraction.

Ectopic renal pain was defined as the first clinical presentation with renal pain in a distant anatomical location without involvement of its original site or renal pain that is caused by an unusual etiology making it the first clinical presentation of this etiology without being expected in the natural history of etiology. The events were categorized according to the relation of the sites of primary pathology and first pain presentation to the upper urinary tract. First group included only patients who had isolated distant-site renal pain without original site pain at first presentation. Second group included patients who had non-urological pathology which was presented for the first time with renal pain. This categorization was proposed to differentiate the urological and the non-urological origin of the pathology and the cause of the unusual presentation. Each case was studied for the relevant demographic variables, anatomical side of pain start, duration of pain, primary disease, diagnostic methods, and management approach.

Cases of referred pain with original site involvement at first presentation were excluded. Also, cases of ectopic kidneys which are presented by unusual pain such as lower abdominal pain were excluded from the study, because their etiology could be explained accordingly. Moreover, cases of misdiagnoses of appendicitis or biliary colic as renal colic were excluded, because the cause is a failure of diagnosis rather than a symptom aberrance.

\section{Results}

The rate of attendance to our outpatient clinic was about 100 cases per day giving more than 360,000 patients in 15 years. Loin or renal pain was the cardinal presentation in more than 135,000 patients. Among the latter patients, only 24 cases $(0.018 \%)$ had isolated unusual renal pain that fulfilled the definition of ectopic renal pain as a first clinical presentation. Age range was 7-61 years with an average of $31.6 \pm 13.3$ years. They were 15 males and 9 females including 2 children only.

According to the original pathology and the site of first pain presentation in relation to the urinary system, 2 groups of patients could be differentiated. The first group (Table 1) included 15 cases $(62.5 \%)$ of isolated distant-site renal pain manifestation. They included isolated forms of contralateral renal pain in 3 cases (12.5\%), epigastric cramps in 3 cases (12.5\%), low-back pain in 4 cases $(16.7 \%)$, and contralateral testicular pain in 5 cases $(20.8 \%)$. The second group (Table 2) included renal pain due to unusual extra-urological causes in 9 cases (37.5\%). They included cases of refractory acute ischemic renal pain as the first presentation of pathologies in extra-urologic systems in 5 cases (20.8\%) and referred biliary pain in 4 cases $(16.7 \%)$.

All cases were diagnosed after multiple medical consultations of different medical specialties. In most of instances, multiple laboratory and/or imaging examinations were indicated to settle the final diagnosis and treatment (Table 1 \& 2). Only two cases had their consultations and diagnoses during single hospital admission.

Table 1: Demographic and clinical features of cases of primary ectopic renal pain (the first group).

\begin{tabular}{|c|c|c|c|c|c|c|c|c|c|}
\hline \multirow{2}{*}{ No } & \multirow{2}{*}{ Age } & \multirow{2}{*}{ Gender } & \multicolumn{2}{|c|}{$\begin{array}{c}\text { Primary Urinary Pathol- } \\
\text { ogy }\end{array}$} & \multicolumn{2}{|c|}{ Ectopic Pain } & \multirow{2}{*}{$\begin{array}{l}\text { Frequency of } \\
\text { Consultation }\end{array}$} & \multirow{2}{*}{$\begin{array}{l}\text { Undue Investiga- } \\
\text { tions }\end{array}$} & \multirow{2}{*}{ Treatment } \\
\hline & & & Site & Nature & Site & Duration & & & \\
\hline 1 & 34 & Female & $\begin{array}{l}\text { Right } \\
\text { ureter }\end{array}$ & Stone & Left loin & 2 weeks & 2 & None & ESWL \\
\hline 2 & 33 & Female & $\begin{array}{l}\text { Right } \\
\text { ureter }\end{array}$ & Stone & Left loin & 3 weeks & 2 & None & ESWL \\
\hline 3 & 40 & Male & $\begin{array}{l}\text { Right } \\
\text { ureter }\end{array}$ & Stone & Left loin & 7 days & 2 & None & URS \\
\hline 4 & 20 & Male & $\begin{array}{l}\text { Right } \\
\text { ureter }\end{array}$ & Stone & Epigastric pain & 2 months & 3 & None & Conservative \\
\hline 5 & 22 & Male & $\begin{array}{l}\text { Left } \\
\text { ureter }\end{array}$ & Stone & Epigastric pain & 2 years & 5 & Upper GIT endos & Conservative \\
\hline 6 & 31 & Male & $\begin{array}{l}\text { Right } \\
\text { ureter }\end{array}$ & Stone & Epigastric pain & 2 months & 2 & None & ESWL \\
\hline 7 & 27 & Male & $\begin{array}{l}\text { Left } \\
\text { ureter }\end{array}$ & Stone & Low back pain & 10 months & 5 & MRI spine & URS \\
\hline 8 & 36 & Male & $\begin{array}{l}\text { Left } \\
\text { ureter }\end{array}$ & Stone & Low back pain & 7 months & 4 & MRI spine & URS \\
\hline
\end{tabular}




\begin{tabular}{|c|c|c|c|c|c|c|c|c|c|}
\hline 9 & 29 & Female & $\begin{array}{l}\text { Right } \\
\text { ureter }\end{array}$ & Stone & Low back pain & 3 months & 4 & None & URS \\
\hline 10 & 44 & Female & $\begin{array}{c}\text { Left } \\
\text { ureter }\end{array}$ & Stone & Low back pain & 5 weeks & 3 & None & URS \\
\hline 11 & 17 & Male & $\begin{array}{l}\text { Right } \\
\text { ureter }\end{array}$ & Stone & Left testicular pain & 2 months & 2 & None & URS \\
\hline 12 & 32 & Male & $\begin{array}{c}\text { Left } \\
\text { ureter }\end{array}$ & Stone & Right testicular pain & 2 weeks & 2 & Scrotal Doppler & Conservative \\
\hline 13 & 26 & Male & $\begin{array}{c}\text { Left } \\
\text { ureter }\end{array}$ & Stone & Right testicular pain & 3 weeks & 2 & Scrotal Doppler & ESWL \\
\hline 14 & 21 & Male & $\begin{array}{l}\text { Right } \\
\text { ureter }\end{array}$ & Stone & Left testicular pain & 5 weeks & 3 & Scrotal Doppler & Conservative \\
\hline 15 & 18 & Male & $\begin{array}{c}\text { Left } \\
\text { ureter }\end{array}$ & Stone & Right testicular pain & 4 weeks & 3 & Scrotal Doppler & URS \\
\hline
\end{tabular}

Abbreviations: ESWL: Extracorporeal Shock Wave Lithotripsy; GIT endos: Gastrointestinal Tract Endoscopy; IVU: Intravenous Urography; URS: Ureteroscopy

Table 2: Demographic and clinical features of cases of secondary ectopic renal pain (the second group).

\begin{tabular}{|c|c|c|c|c|c|c|c|c|c|c|}
\hline \multirow{2}{*}{ No } & \multirow{2}{*}{ Age } & \multirow{2}{*}{ Gender } & \multicolumn{3}{|c|}{ Renal Pain } & \multicolumn{2}{|c|}{ Primary Pathology } & \multirow{2}{*}{$\begin{array}{l}\text { Frequency of } \\
\text { Consultation }\end{array}$} & \multirow{2}{*}{$\begin{array}{l}\text { Undue Investi- } \\
\text { gation }\end{array}$} & \multirow{2}{*}{ Treatment line } \\
\hline & & & Side & Duration & $\begin{array}{l}\text { Renal } \\
\text { Effect }\end{array}$ & System & Pathology & & & \\
\hline 1 & 38 & Male & Left & 3 days & Infarction & Blood & Leukemia & 3 & KUB, ECT & Chemotherapy \\
\hline 2 & 44 & Male & Left & 2 days & Infarction & Blood & Leukemia & 2 & ECT & Chemotherapy \\
\hline 3 & 27 & Female & Bilateral & 3 days & Infarction & Immunity & SLE & 3 & ECT & Steroids \\
\hline 4 & 36 & Female & Right & 6 months & PUJO & Biliary tract & Stone & 3 & NEMSCT & ERCP \\
\hline 5 & 46 & Female & Right & 3 months & PUJO & Biliary tract & Stone & 3 & NEMSCT & ERCP \\
\hline 6 & 7 & Female & Right & 1 day & None & Biliary tract & Stone & 4 & NEMSCT & Cholecystectomy \\
\hline 7 & 12 & Female & Right & 1 day & None & Biliary tract & Stone & 3 & NEMSCT & Cholecystectomy \\
\hline 8 & 61 & Male & Right & 1 month & Metastasis & Unknown & Malignancy & 3 & KUB & Palliative \\
\hline 9 & 58 & Male & Left & 2 weeks & Metastasis & Unknown & Malignancy & 2 & KUB & Palliative \\
\hline
\end{tabular}

Abbreviations: ECT: Enhanced Computed Tomography: ERCP: Endoscopic Retrograde Cholangiopancreatography; KUB: Kidney-Ureter-Bladder; X-Ray Radiograph; NEMSCT: Non-Enhanced Multi-Slice Computed Tomography; PUJO: Pelvi-Ureteral Junction Obstruction; SLE: Systemic Lupus Erythematosus.

\section{Discussion}

The upper urinary tract is composed of the kidneys and ureters which have complex retroperitoneal anatomy and physiological mechanisms including the reno-ureteral peristalses and visceral sensations $[3,6,11]$. In the context of the current results, it may be crucial to carefully address a few issues at the start of discussion to avoid any potential confusion with similar notions in the natural history of renal pain which may evolve while this discussion is progressing. The classic pain reference is associated with the typical renal pain in the ipsilateral loin and it is an expected presentation [12]. Renal infarction could be an event in the natural history of the potentially thromboembolic diseases and result in severe renal pain. However, its diagnosis could be overlooked due to rarity of this condition [13]. Also, it is unusual for renal pain to present as the first symptom in such cases [14]. Discussion of the underlying anatomical and pathophysiological aspects, clinical forms, effects on diagnosis and management of these cases are essential to differentiate these notions.

Renal pain is the cardinal symptom of the upper urinary tract diseases $[4,8]$. Occasionally, renal pain or colic may manifest in an unusual site or form, either, caused by urological or nonurological diseases [15]. Pathophysiologically, it is an acute or chronic sensory complex urinary symptom with variable reflexes based on the anatomical and physiological integrations to the other parts of the body [3]. It has significant clinical properties and wide interests in the literature $[4,12]$. It is usually felt in the costovertebral (renal) angle in relation to the kidneys and takes its character according to the underlying cause. It becomes a dull ache, when it is caused by distension of renal capsule. It becomes colicky, however, when it is caused by ureteral obstruction with 
propagation of the peristalses into strong spasmodic contractions. Moreover, it may radiate through the ipsilateral flank and groin or be referred to the ipsilateral testis and the penis leading to variable pain sensations in these sites. Also, it is commonly associated with nausea and vomiting. These radiation and reference manifestations are classically known due to the common innervations between the urinary tract which is supplied by the renal nerve plexus and the biliary and gastrointestinal tracts which are supplied by the celiac nerve plexus $[3,8,16-18]$.

Kidneys have rich sympathetic innervations that directly contact their functional structures such as vasculatures, renal tubules, juxtaglomerular granular cells, and excretory renal tracts. Sensory fibers are located primarily around the renal pelvis. Stimulation of these sympathetic nerves may induce contralateral diuresis as a compensatory reno-renal integration system [19,20]. Also, these fibers transmit pain sensations from other abdominal viscera due to overlapping between nerve plexuses $[3,21]$. These neurological integrations may explain the contralateral pain between the kidneys and ureters [22]. According to the current results, we proposed the term "ectopic renal pain" to withstand the meanings of these unusual clinical forms under one conclusive and representative term.

The first group represented ectopy of the pain site such as the contralateral side which has been previously known as the "mirror pain" [22] and diffuse abdominal cramps [16]. This pattern of presentation could be termed as "primary ectopic renal pain", because the original pathology is a urological one. The isolated form of pain in those patients resulted in delayed diagnosis and indicated extra investigations. The old concept of common innervations may be employed for explanation of these forms of renal pain aberrance [3].

The second group represented ectopy of etiology. This pattern of renal pain could be termed as "secondary ectopic renal pain", because the original pathology is a non-urological one. Presence of previously mentioned dual reno-renal reflexes [19,20] may indicate presence of similar dual reflexes between the urinary tract and biliary and gastrointestinal tracts. Underlying facts of the dynamics of the pelviureteral complex including the regulating factors, mechanisms, and neuromuscular configurations such as common innervation distribution between the body organs and structures may be still not fully understood [3,11]. We proposed that the scenario of functional or spasmodic pelvi-ureteral junction obstruction in response to biliary obstruction could be attributed to a neuromuscular reflex similar to the proposed mechanism of reflex anuria after abdominopelvic manipulations [23]. Clearly, it is not a state of differential diagnosis of a biliary colic from a renal colic. However, it is an ectopic manifestation of biliary obstruction in the picture of renal colic with an underlying functional obstruction. Also, it may represent a paradoxical form of the commonly known referred reflexes of renal colic such as nausea and vomiting. Here, the reflex referred from the biliary tract to the pelvi-ureteral junction inducing its obstruction and renal colic. This form of renal pain ectopia is secondary to a non-urological disorder. Accordingly, it should be differentiated from the ectopic pain resulting from a primary urinary disease.

The effect of biliary tract distension on the systemic arterial flow including the renal circulation has been proposed clinically, but without statistical documentation [8]. Also, the strong associations between the upper urinary and gastrointestinal tracts have been extensively studied with more focusing on the gastrointestinal reflexes or responses to the renal and ureteral obstructions $[7,24]$. These studies targeted mainly the gastrointestinal manifestations due to genitourinary disorders. Terms such as "renal digestive reflex", "renogastric reflex" and "retroperitoneal syndrome" have been coined. However, the paradoxical isolated urological manifestations due to the biliary and gastrointestinal diseases have been reported as rare subjects and seemed to be not sufficiently addressed $[25,26]$. Also, parallel to the chest manifestations of biliary disorders [27], urinary reflexes could be proposed.

Acute renal infarction is an infrequent urological emergency which is often confused with renal colic due to initial unpredictability and mimicking to renal colic of urinary stones. When it presents as an initial presentation of a major disease, it may bypass the chance for salvage of the kidney due to late presentation $[13,28]$. This scenario occurred in three patients of the current series. One of them had systemic lupus erythematosus and experienced bilateral renal infarctions which progressed to end stage renal disease.

Atypical clinical presentations of diseases including the uncommon causes of abdominal pain still represent serious situations in the emergency medicine, because they may occur suddenly in young patients who appear otherwise healthy [29]. These uncommon causes of a given symptom may make it unusually as the first presentation. Example for this scenario is acute renal infarction in cases of undiscovered thromboembolic risks [28]. This scenario was represented in the second group of the current study.

Non-urological causes of loin pain should not be confused with the "secondary ectopic renal pain" and this is a critical point in management of these cases. This notion has been highlighted elsewhere in this discussion and previous studies, but it should be addressed clearly at the end. The former issue is a relatively known practical mistake based on the high-degree of similarity between different presentations [21], while the latter issue is a real renal pain with a kidney insult aberrantly caused by uncommon or unusual etiology. Really, although this issue is a very rare subject in the emergency medicine, it warrants alertness of the emergency physicians including the urologists. The proposed hypotheses for its etiology look highly speculative, but this subject may represent a new horizon for further studying of renal pain mechanisms.

\section{Conclusion}

Renal pain is a complex urological symptom with very rare unusual clinical expressions which are caused by different etiologies. They can be ectopic in site as a referred pain based on the neural intercommunications or ectopic in etiology due to unusual non-urological pathology. Ectopy of renal pain may delay 
the diagnosis of the original diseases and consume financial and mental resources. Accordingly, it should be considered in mind, when the cause of renal pain is not obvious and in the cases of unexplained abdominal pain.

\section{References}

1. The British Medical Association (BMA) (2002) Illustrated Medical Dictionary a Dorling Kindersley Book, p. 406.

2. Kaura KS, Kumar M, Sokhal AK, Gupta AK, Purkait B, et al. (2017) Giant hydronephrosis: still a reality! Turk J Urol 43(3): 337-344.

3. Pedersen KV, Drewes AM, Møller FPC, Osther PJ (2010) Visceral pain originating from the upper urinary tract. Urol Res 38(5): 345-355.

4. Travaglini F, Bartoletti R, Gacci M, Rizzo M (2004) Pathophysiology of reno-ureteral colic. Urol Int 72(Suppl 1): 20-23.

5. Jewell NP (2016) Natural history of diseases: Statistical designs and issues. Clin Pharmacol Ther 100(4): 353-361.

6. Hickling DR, Sun TT, Wu XR (2015) Anatomy and physiology of the urinary tract: Relation to host defense and microbial infection. Microbiol Spectr 3(4): 1-29.

7. Katz AB (1953) Gastro-intestinal manifestations of urinary tract disease. J Urol 69(5): 726-733.

8. Corbitt JD, Levin JM, Walker LJ, Haynes CD (1970) Relationship between biliary tract distention and the blood flow in the aorta and right coronary and renal arteries. Am J Surg 120(1): 14-15.

9. Bueschen AJ, Flank Pain (1990) In: Walker HK, et al. (Eds.), Clinical methods: The history, physical, and laboratory examinations. (3rd edn), Butterworths, Boston, Massachusetts, USA, pp. 845-846.

10. Waheed S, Baig MA, Khan MW, Sheikh FA, Khan NU (2016) Fungal endocarditis presenting with right lumbar pain and femoral artery ischemia-An unusual case report. Turk J Emerg Med 16(4): 173-175.

11. Santicioli P, Maggi CA (1980) Myogenic and neurogenic factors in the control of pyeloureteral motility and ureteral peristalsis. Pharmacol Rev 50(4): 683-722.

12. Shokeir AA (2002) Renal colic: new concepts related to pathophysiology, diagnosis and treatment. Curr Opin Urol 12(4): 263-269.

13. Salih SB, Durihim AH, Jizeeri AA, Maziad AG (2006) Acute renal infarction secondary to atrial fibrillation-mimicking renal stone picture. Saudi Kidney Dis Transpl 17(2): 208-212.
14. Kuzmanovska DB, Sahpazova EM, Grujovska SJ, Trajkovski Z (2004) Renal infarction in a child with systemic lupus erythematosus. Pediatr Nephrol 19(6): 685-687.

15. Lalosević $D$ (2009) Acute renal pain as an adverse reaction of the rabies immunization. Med Pregl 62(3-4): 133-135.

16. Teichman JM (2004) Clinical practice. Acute renal colic from ureteral calculus. N Engl J Med 350(7): 684-693.

17. Leung AK, Robson WL, Ng AC (2007) Ureteral calculus presenting as generalized abdominal cramps. J Natl Med Assoc 99(7): 802-805.

18. Golzari SE, Soleimanpour H, Rahmani F, Mehr ZN, Safari S, et al. (2014) Therapeutic approaches for renal colic in the emergency department: a review article. Anesth Pain Med 4(1): e16222.

19. Johns EJ, Kopp UC, DiBona GF (2011) Neural control of renal function. Compr Physiol 1(2): 731-767.

20. Kopp UC (1992) Renorenal reflexes: interaction between efferent and afferent renal nerve activity. Can J Physiol Pharmacol 70(5): 750-758.

21. Rucker CM, Menias CO, Bhalla S (2004) Mimics of renal colic: Alternative diagnoses at unenhanced helical CT. Radio Graphics 24(suppl 1): S11-S28.

22. Clark AJ, Norman RW (1998) "Mirror pain" as an unusual presentation of renal colic. Urology 51(1): 116-118.

23. Hou W, Wen J, Ji Z, Li H (2014) Reflex anuria: an old concept with new evidence. Int Urol Nephrol 46(2): 323-328.

24. Shafik A (1998) A study of the effect of renal pelvic and ureteric distention on the anorectal function with identification of the "renoanal reflex". Front Biosci 3(2): b6-b10.

25. Shafik A (1999) Demonstration of a "renogastric reflex" after rapid distension of renal pelvis and ureter in nonanesthetized patients. Urology 53(1): 38-43.

26. Smith E, Orkin L (1940) The renal digestive reflex. J Urol 43(1): 1-19.

27. Durning SJ, Nasir JM, Sweet JM, Cation LJ (2006) Chest pain and ST segment elevation attributable to cholecystitis: a case report and review of the literature. Mil Med 171(12): 1255-1258.

28. Iglesia FDL, Asensio P, Díaz A, Darriba M, Nicolás R, et al. (2003) Acute renal infarction as a cause of low-back pain. South Med J 96(5): 497-499.

29. Grubb SM, Stuart JI, Harper HM (2017) Sudden onset flank pain. Spontaneous renal rupture. Am J Emerg Med 35(11): 1787 e1-1787e3.

For possible submissions Click below: 